\title{
Original
}

\section{Diagnosis accuracy of two vision screeners for visual health surveillance of workers who use video display terminals}

\author{
María-José Molina-Torres ${ }^{1,2}$, María-del-Mar Seguí Crespo ${ }^{3,4}$, Ana Tauste Francés ${ }^{2}$, \\ Blanca Lumbreras Lacarra ${ }^{5,6}$ and Elena Ronda-Pérez ${ }^{4,6,7,8}$
}

\begin{abstract}
${ }^{1}$ Valencian Institute of Occupational Safety and Health (INVASSAT), Alicante, Spain, ${ }^{2}$ Doctorate Programme on Health Science, University of Alicante, Spain, ${ }^{3}$ Department of Optics, Pharmacology and Anatomy, University of Alicante, Spain, ${ }^{4}$ Public Health Research Group, University of Alicante, Spain, ${ }^{5}$ Department of Public Health, History of Science and Gynaecology, University Miguel Hernández, San Juan de Alicante, Spain, ${ }^{6}$ CIBERESP (Consortium for Biomedical Research of Epidemiology and Public Health), Madrid, Spain, ${ }^{7}$ Preventive Medicine and Public Health Area, Faculty of Health Sciences, University of Alicante, Spain and ${ }^{8}$ CISAL (Centre for Research in Occupational Health), Barcelona, Spain
\end{abstract}

\begin{abstract}
Objective: To compare the diagnostic accuracy of two vision screeners by a visual examination performed by an optometrist (gold standard) and to evaluate the concordance between both screeners and between each screener and the gold standard. Methods: This was a cross-sectional study that included computer workers who attended a routine yearly health examination. The study included administrative office workers $(n=$ 91 ) aged $50.2 \pm 7.9$ years (mean \pm standard deviation), $69.2 \%$ of whom were women and $68.1 \%$ of whom used video display terminals (VDT) for $>4 \mathrm{~h} /$ day. The routine visual examination included monocular and binocular distance visual acuity (VA), distance and near lateral phoria (LP), stereo acuity (SA), and color vision. Tests were repeated with Optec 6500 (by Stereo Optical) and Visiotest (by Essilor) screeners. Sensitivity, specificity, positive predictive values (PPV), negative predictive values (NPV), and false positive and negative rates were calculated. Kappa coefficient ( $\kappa$ ) was used to measure the concordance of the screeners and the gold standard. Results: The sensitivity and specificity for monocular VA were over $80 \%$ for both vision screeners; PPV was below $25 \%$. Sensitivity and specificity were lower for SA (55\%-70\%), PPV was $50 \%$, and NPV was $75 \%$ for both screeners. For distance LP, sensitivity and PPV were < $10 \%$ in both cases. The screeners differed in their values for near LP: Optec 6500 had higher sensitivity (43.5\%),
\end{abstract}

Received September 3, 2015; Accepted June 16, 2016

Published online in J-STAGE August 4, 2016

Correspondence to: MJ. Molina-Torres, Valencian Institute of Occupational Safety and Health (INVASSAT), Alicante, Spain (e-mail: molina_jo stor@gva.es)
PPV (37.0\%), and NPV (79.7\%); whereas the Visiotest had higher specificity (83.8\%). For color vision, Visiotest showed low sensitivity, low PPV, and high specificity. Visiotest obtained false positive rates that were lower or similar to Optec 6500, and both screeners obtained false negative rates below $50 \%$. Both screeners showed poor concordance $(\kappa<0.40)$. Conclusions: A high value for NPV would qualify both screeners as acceptable alternatives for visual health surveillance when used as a screening tool; patients with positive test results should be referred to a specialist.

(J Occup Health 2016; 58: 444-451)

doi: 10.1539/joh.15-0247-OA

Key words: Computer terminals, Diagnosis, Occupational health, Vision screening

\section{Introduction}

In recent years, remarkable advances in the use of new information and communication technologies have improved workplace efficiency. The $5^{\text {th }}$ European Work Conditions Survey (EWCS, 2010) ${ }^{1)}$ showed that $30 \%$ of workers used computers during the entire working day, whereas $25 \%$ of workers used computers between one quarter and three-quarters of their working day. Visual demands are higher when working for an extended period of time in front of a computer than those when reading on paper as well as for other near vision tasks ${ }^{2}$. Several studies have also demonstrated the effects of work day computer use on vision ${ }^{3-5)}$. Most workers have experienced increased ocular and visual symptoms with computer use $\mathrm{e}^{6,7)}$, 
and some report that their symptoms worsen when using computers for long periods of time ${ }^{8,9)}$.

Visual health surveillance is essential for the protection of workers who use computers. The European Council Directive 90/270/EEC ${ }^{10)}$ establishes the minimum health and safety requirements for working with display terminals, including computers. In Spain, the Specific Health Surveillance Protocol for Video Display Terminals ${ }^{11}$ ) stipulates that workers who use computers should receive regular health screenings (including anamnesis, a questionnaire on ocular and visual symptoms, and visual tests). In most European countries such as France ${ }^{12)}$ and England $^{13)}$ vision screeners (Visiotest, Optec, Ergovisión, amongst others) are a recommended tool to rapidly perform visual screenings. Vision screeners are simple and easy to use, and have low maintenance costs and thus are considered as a useful tool for prevention services.

Despite these recommendations, only three studies assessing the validity of these screeners have been identified, and two of them were published before $2000^{14,15}$. Horberry et al. ${ }^{14)}$ compared six different types of vision screeners (Vutest, City screening system, Titmus 2, Keystone VS-II, Ergovision, and Optec 2500) and concluded that three of them (Vutest, City screening system, and Ergovision) had high false positive results, whereas results with the other three (Titmus 2, Keystone VS-II, and Optec 2500) were closer to those found with the gold standard (visual examination performed by an optometrist). Hansmaennel et al. ${ }^{15)}$ published an evaluation of the Visiotest (the screener most frequently marketed and used for visual health surveillance in Spain, France, and Italy) ${ }^{16)}$ and showed that the screener had a high negative predictive value (NPV) and generated a high number of false positives ( $>50 \%$ ), especially when measuring stereoscopic vision and phorias. Totaro et al. ${ }^{17)}$ aimed to validate the $\mathrm{Er}$ govision screener in a sample of 100 computer workers; however, this screener also showed a high number of false positive results. In all of the foregoing studies, the specific visual examination conducted by visual health specialists (ophthalmologists and/or optometrists) was considered to be the gold standard.

The aforementioned studies do not indicate the intervals of normality for comparison to establish whether the test was altered. Two of them only report that the test values were obtained following the manufacturer's criteria $^{14,15)}$, whereas the third study does not address this issue at all ${ }^{17)}$. This, combined with the fact that European standards recommend the use of these devices, that the number of workers who use video display terminals (VDT) is increasing, and that the few validation studies conducted to date show a high percentage of false positives and differences among screeners, indicates that new studies are required to evaluate the accuracy of the new models of screeners used in prevention services. It is also important to determine what patient characteristics that are known to be related to the prevalence of several kinds of visual alterations (such as sex, age, and VDT use) are related to differences in the accuracy of the screeners.

The objective of this study was to compare the diagnostic accuracy of two vision screeners that are currently used in visual health surveillance of VDT users with a visual examination performed by an optometrist as the gold standard taking into consideration the sex, age, and VDT use of the study participants. We also evaluated the concordance between the two screeners and between each screener and the gold standard in the diagnosis of altered visual tests.

\section{Materials and Methods}

\section{Study design and participants}

This was a cross-sectional study that included public administrative office workers in Alicante, Spain. Random days were chosen between October and November 2013; all of the computer workers that attended a routine yearly health surveillance examination at the occupational prevention services on those days were included in this study. All of the subjects agreed to participate $(n=91)$. An exclusion criterion was established for those who were undergoing treatment for an ocular pathology at the time of the examination, but this criterion did not apply to any of the participants in this study.

When scheduling patients for their yearly examination, the prevention service provided them with instructions to be followed prior to their visit. Among other general instructions, all contact lens users were told to discontinue their use for $48 \mathrm{~h}$ prior to their appointment and to bring their corresponding glasses with them if they are ametropic. These instructions were maintained in the present study.

\section{Personal data}

Data on the history of ocular health, sex, age, and the number of daily hours spent working with a computer were collected through a structured self-administered questionnaire.

\section{Gold standard}

An expert optometrist conducted the visual examination for all the subjects included in the study, which comprised the following tests: monocular and binocular distance visual acuity (VA), distance and near lateral phoria (LP), stereo acuity (SA), and color vision. The tests that were selected were recommended by the protocol for health surveillance of VDT users in Spain ${ }^{11}$, which in turn are based on the Council Directive 90/270/EEC ${ }^{10)}$.

VA was measured monocularly and binocularly using the Early Treatment Diabetic Retinopathy Study (ETDRS) chart with the workers' habitual refractive correction. If the acuity was $<20 / 20$ in either eye, then a 


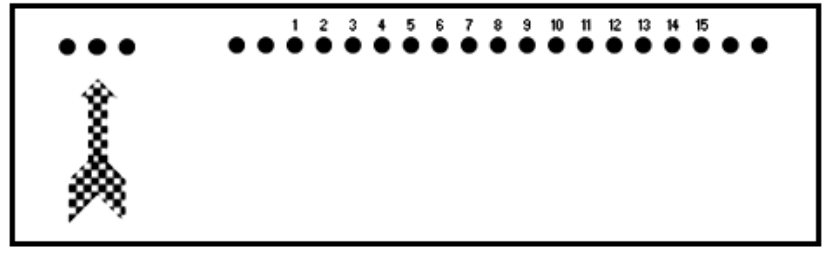

(a)

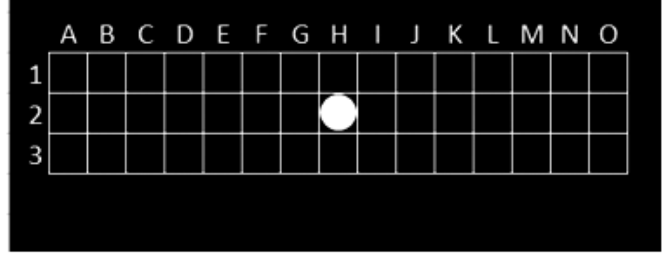

(b)

Fig. 1. Chart to measure distance lateral phoria with Optec 6500 (a) and Visiotest (b).

complete subjective refraction was performed using autorefractor findings as the starting point. If the acuity improved by more than one line $(\geq 0.1 \log$ MAR) after subjective refraction, then the acuity measurements and the rest of the tests were conducted with the new refraction worn in a trial frame. VA was scored as the total number of letters read correctly and converted to $\log$ MAR according to the method recommended by Bailey and LovieKitchin ${ }^{18)}$. The cut-off point that was established to indicate an altered test was VA>0.0 $\log \mathrm{MAR}^{18,19)}$.

The cover test allowed for the evaluation of the presence, direction, and magnitude of LP. A cover-uncover test was conducted to determine the absence of manifest strabismus or tropia. Afterwards, an alternate cover test was conducted to detect and measure the possible existence of LP (esophoria or exophoria) using a LUNEAU horizontal prism bar. Both tests were conducted for distance and near $(40 \mathrm{~cm})$ fixation. Exophoria greater than three prism diopters and esophoria greater than one prism diopter were considered to be outside of the normal range for distance LP, and exophoria greater than six prism diopters and any esophoria were considered outside the normal range for near $\mathrm{LP}^{20)}$.

The Titmus stereotest (Wirt circles) was used to measure SA. This test was performed at a distance of $40 \mathrm{~cm}$ while the participant wore polarizing spectacles; the lowest disparity that the participants were able to detect was recorded as their SA in seconds of arc. An SA value of greater than $50 \mathrm{~s}$ of arc was considered as altered ${ }^{21)}$.

Binocular inspection of Ishihara plates 1-25 (38-plate edition) was used to determine the existence of red-green color deficiencies. A correct reading of 17 or more plates is considered normal ${ }^{22)}$.

\section{Diagnostic tests}

An occupational health nurse conducted the evaluation using the vision screeners Optec 6500 (by Stereo Optical) and Visiotest (by Essilor) (the Ishihara test could only be used with the Visiotest). These are the devices that are most commonly used in the occupational risk prevention service for surveillance of workers' visual health.

The external characteristics of the Optec 6500 and $\mathrm{Vi}$ siotest were similar. Their height could be adjusted, and they were equipped with a headrest. However, they had some ergonomic differences. The lights in the Optec 6500 were activated only when the subject maintained pressure against the forehead rest, which assured that the distance from the participant's eyes to the chart was correct; this was not the case with the Visiotest. Although they both had an occlusor system that allowed for the isolation of one eye from the other and thus for the performance of monocular and binocular tests, the Optec 6500 had two vision areas (an upper one for observation of charts when testing far distance vision and a lower one for observation of charts when testing near distance vision). The Visiotest had only one vision area. The charts were also different. As an example, see Fig. 1 for the case of distance LP.

The examinations were made with the refractive correction that was previously completed by the optometrist in the visual examination worn in a trial frame. Each manufacturer established its own method to interpret the test results, which depended on the characteristics of its screener; we proceeded in accordance with those instructions to obtain the values for each test. The normality ranges according to the scientific literature allowed for the classification of each test as altered or not altered both for the two screeners and for the gold standard. These normality ranges have been previously described above for each test (in gold standard section).

The examiners (optometrist and occupational health nurse) performed the tests after a period of formal training. All of the tests were made on the same day. The gold standard was performed prior to the diagnostic tests independently and blindly of the diagnostic test results. The diagnostic tests were also performed independently and blindly from the gold standard results. The order of screener use was randomized in this study. Neither the optometrist nor the occupational health nurse knew the participants' personal data or their daily hours spent using a computer. The examiners provided the relevant instructions to the participants before each test. To aid these explanations, they each had a template showing a picture of the charts.

All participants provided informed consent for this study. Confidentiality of the participants' results was guaranteed at all times. This study has followed the recommendations established in the STARD checklist ${ }^{23}$. 
Table 1. Prevalence of altered tests on the visual examination conducted by an optometrist according to the workers' characteristics

\begin{tabular}{|c|c|c|c|c|c|c|c|c|c|c|}
\hline \multirow{2}{*}{ Test } & \multirow{2}{*}{ Total } & \multicolumn{3}{|c|}{ Sex } & \multicolumn{3}{|c|}{ Age (years) } & \multicolumn{3}{|c|}{$\begin{array}{l}\text { Computer use at work } \\
\text { (h/day) }\end{array}$} \\
\hline & & Men & Women & $p$ value & $\leq 50$ & $>50$ & $p$ value & $\leq 4$ & $>4$ & $p$ value \\
\hline Monocular $\mathrm{VA}^{\dagger}(\log M A R)$ & 3.3 & 3.6 & 3.2 & 0.890 & 0.0 & 6.0 & $0.024 *$ & 1.7 & 4.0 & 0.416 \\
\hline $\mathrm{SA}(\operatorname{arcsec})$ & 34.1 & 32.1 & 34.9 & 0.796 & 19.5 & 46.0 & $0.008^{*}$ & 37.9 & 32.3 & 0.595 \\
\hline Distance LP $(\Delta)$ & 12.1 & 3.6 & 15.9 & 0.097 & 12.2 & 12.0 & 0.977 & 20.7 & 8.1 & 0.085 \\
\hline Near LP $(\Delta)$ & 25.3 & 14.3 & 30.2 & 0.108 & 24.4 & 26.0 & 0.860 & 27.6 & 24.2 & 0.729 \\
\hline Color vision & 2.2 & 0.0 & 3.2 & 0.340 & 0.0 & 4.0 & 0.195 & 0.0 & 3.2 & 0.328 \\
\hline
\end{tabular}

Abbreviations: VA, visual acuity; SA, stereo acuity; LP, lateral phoria; $\Delta$, prism diopters.

${ }^{\dagger}$ Monocular VA was calculated for both eyes $(\mathrm{n}=182)$.

*Significant at $p<0.05$.

\section{Statistical analysis}

A descriptive analysis was performed (mean, standard deviation, range, and absolute and relative frequencies). The prevalence of altered tests was calculated according to sex, age $(\leq 50$ and $>50$ years according to the mean age), and the number of hours spent per day using a computer at work $(<4$ and $>4 \mathrm{~h}$, in accordance with the criteria for health surveillance $)^{11}$; this data was compared using the Chi-squared test. $P$ values of $<0.05$ were considered statistically significant. To study the precision in the diagnosis of the Optec 6500 and Visiotest, each of the results obtained from these screeners and from the examination by the optometrist (gold standard) were compared by calculating the sensitivity, specificity, positive predictive value (PPV), and NPV together with the confidence interval (CI) at $95 \%$ (the Wilson interval for simple proportions was used $)^{24}$. False positive and false negative rates were also calculated as (1-specificity) and (1-sensitivity), respectively. Results for monocular VA were determined by analyzing both eyes of each participant $(n=182)$ and the rest of the tests were conducted binocularly $(n=91)$. To measure the concordance, the Kappa coefficient $(\kappa)$ was used to compare between each vision screener and the gold standard, as well as between the two screeners. A $\kappa$ higher than 0.75 was considered good concordance, between $0.40-0.75$ was considered moderate concordance, and $<0.40$ was considered poor concordance ${ }^{25)}$. The SPSS 15.0 statistics program for Windows ${ }^{\mathrm{TM}}$ and EPIDAT 4.0 program were used to analyze the data.

\section{Results}

\section{Demographic and clinical characteristics (Table 1)}

Ninety-one workers were included in the study $(30.8 \%$ men and $69.2 \%$ women). The age was $50.2 \pm 7.9$ (mean \pm standard deviation) years, with a range of 26 to 65 years. These participants used computers for a mean of $5.3 \pm 1.6$ $\mathrm{h}$ per day, with a range of $2-8 \mathrm{~h} ; 68.1 \%$ used computers for more than $4 \mathrm{~h}$ per day.
Table 1 shows the prevalence of altered tests on the visual examination conducted by an optometrist according to the workers' characteristics. SA $(34.1 \%)$ and near LP $(25.3 \%)$ had the highest prevalence of altered tests. In general, women and participants $>50$ had the highest prevalence of altered tests, and there were statistically significant differences for monocular VA and in SA according to age. In binocular VA, no test results differed from normal values; all workers reached the VA unit with regard to their binocular vision.

\section{Accuracy of the two visual screeners (Table 2)}

Both vision screeners had high $(>80 \%)$ sensitivity and specificity for monocular VA. However, sensitivity and specificity were lower for SA with both screeners (between 55\%-70\%), PPV was 50\%, and NPV was $75 \%$. For distance LP, the vision screeners showed low values in sensitivity and the PPV was below $10 \%$. The screeners differed with regard to near LP results: sensitivity (43.5\%), PPV (37.0\%), and NPV (79.7\%) were higher in the Optec 6500; specificity was higher in the Visiotest $(83.8 \%)$. In the Visiotest results for color vision, sensitivity was $50.0 \%$ and PPV was $11.1 \%$, whereas specificity and NPV were both high $(>90 \%)$.

The false positive rate of the Optec 6500 was $17.0 \%$ for monocular AV, $1.1 \%$ for binocular AV, 26.2\% for distance LP, $25.0 \%$ for near LP, and $35.0 \%$ for SA. In the case of the Visiotest, lower false positive values were obtained for monocular AV (11.9\%), near LP (16.2\%), and SA $(31.7 \%)$, whereas higher values were obtained for binocular AV (3.3\%) and distance LP (27.5\%); for color vision, the false positive rate of the Visiotest was $9.0 \%$. The Optec 6500 false negative rate was $16.7 \%$ for monocular AV, $41.9 \%$ for SA, $90.9 \%$ for distance LP, and $56.5 \%$ for near LP. The Visiotest false negative rate was $0.0 \%$ for monocular VA, $35.5 \%$ for SA, $90.9 \%$ for distance LP, $87.0 \%$ near LP, and $50.0 \%$ for color vision. 
Table 2. Sensitivity (S), specificity (Sp), positive predictive value (PPV) and negative predictive value (NPV) with their corresponding confidence intervals at 95\% (95\% CI) when comparing Optec 6500 and Visiotest vision screeners with the visual examination conducted by an optometrist

\begin{tabular}{|c|c|c|c|c|c|c|c|c|}
\hline \multirow{2}{*}{ Test } & \multicolumn{2}{|c|}{$\mathrm{S}(95 \% \mathrm{CI})$} & \multicolumn{2}{|c|}{$\mathrm{Sp}(95 \% \mathrm{CI})$} & \multicolumn{2}{|c|}{ PPV $(95 \%$ CI $)$} & \multicolumn{2}{|c|}{ NPV (95\% CI) } \\
\hline & Optec 6500 & Visiotest & Optec 6500 & Visiotest & Optec 6500 & Visiotest & Optec 6500 & Visiotest \\
\hline $\begin{array}{l}\text { Monocular VA } \\
(\log M A R)\end{array}$ & $\begin{array}{c}83.3 \\
(43.7-97.0)\end{array}$ & 100.0 & $\begin{array}{c}83.0 \\
(76.7-87.8)\end{array}$ & $\begin{array}{c}88.1 \\
(82.5-92.1)\end{array}$ & $\begin{array}{c}14.3 \\
(6.3-29.4)\end{array}$ & $\begin{array}{c}22.2 \\
(10.6-40.8)\end{array}$ & $\begin{array}{c}99.3 \\
(96.3-99.9)\end{array}$ & 100.0 \\
\hline $\begin{array}{l}\text { Binocular } \mathrm{VA}^{\dagger} \\
(\log M A R)\end{array}$ & - & - & $\begin{array}{c}98.9 \\
(94.0-99.8)\end{array}$ & $\begin{array}{c}96.7 \\
(90.8-98.9)\end{array}$ & - & - & 100.0 & 100.0 \\
\hline $\begin{array}{l}\mathrm{SA} \\
(\operatorname{arcsec})\end{array}$ & $\begin{array}{c}58.1 \\
(40.8-73.6)\end{array}$ & $\begin{array}{c}64.5 \\
(47.0-78.9)\end{array}$ & $\begin{array}{c}65.0 \\
(52.4-75.8)\end{array}$ & $\begin{array}{c}68.3 \\
(55.8-78.7)\end{array}$ & $\begin{array}{c}46.2 \\
(31.6-61.4)\end{array}$ & $\begin{array}{c}51.3 \\
(36.2-66.1)\end{array}$ & $\begin{array}{c}75.0 \\
(61.8-84.8)\end{array}$ & $\begin{array}{c}78.9 \\
(66.0-87.8)\end{array}$ \\
\hline $\begin{array}{l}\text { Distance LP } \\
(\Delta)\end{array}$ & $\begin{array}{c}9.1 \\
(1.6-37.7)\end{array}$ & $\begin{array}{c}9.1 \\
(1.6-37.7)\end{array}$ & $\begin{array}{c}73.8 \\
(63.2-82.1)\end{array}$ & $\begin{array}{c}72.5 \\
(61.9-81.1)\end{array}$ & $\begin{array}{c}4.6 \\
(0.8-21.8)\end{array}$ & $\begin{array}{c}4.4 \\
(0.8-21.0)\end{array}$ & $\begin{array}{c}85.5 \\
(75.3-91.9)\end{array}$ & $\begin{array}{c}85.3 \\
(75.0-91.8)\end{array}$ \\
\hline Near LP $(\Delta)$ & $\begin{array}{c}43.5 \\
(25.6-63.2)\end{array}$ & $\begin{array}{c}13.0 \\
(4.5-32.1)\end{array}$ & $\begin{array}{c}75.0 \\
(63.6-83.8)\end{array}$ & $\begin{array}{c}83.8 \\
(73.3-90.7)\end{array}$ & $\begin{array}{c}37.0 \\
(21.5-55.8)\end{array}$ & $\begin{array}{c}21.4 \\
(7.6-47.6)\end{array}$ & $\begin{array}{c}79.7 \\
(68.3-87.7)\end{array}$ & $\begin{array}{c}74.0 \\
(63.3-82.5)\end{array}$ \\
\hline Color vision $\ddagger$ & & $\begin{array}{c}50.0 \\
(9.5-90.6)\end{array}$ & & $\begin{array}{c}91.0 \\
(83.3-95.4)\end{array}$ & & $\begin{array}{c}11.1 \\
(2.0-43.5)\end{array}$ & & $\begin{array}{c}98.8 \\
(93.4-99.8)\end{array}$ \\
\hline
\end{tabular}

Abbreviations: VA, visual acuity; SA, stereo acuity; LP, lateral phoria; $\Delta$, prism diopters.

${ }^{\dagger} \mathrm{S}$ and PPV could not be calculated as no altered test results were obtained according to the gold standard.

*Test was not conducted with the Optec 6500 .

Accuracy by sex, age, and number of daily hours of computer use at work (Table 3)

Table 3 shows the data stratified according to sex, age, and number of hours per day spent using a computer at work. The largest differences between screeners for male participants were in monocular VA for sensitivity (Optec $6500,50.0 \%$ vs. Visiotest, 100.0\%) and PPV (Optec $6500,20.0 \%$ vs. Visiotest, $66.7 \%$ ). For female participants, the largest differences between screeners were in near LP for sensitivity (Optec 6500, 47.4\% vs. Visiotest, $10.5 \%$ ) and PPV (Optec 6500, 52.9\% vs. Visiotest, $22.2 \%)$. For participants $\leq 50$, the largest differences between screeners were in near LP for sensitivity (Optec $6500,30.0 \%$ vs. Visiotest, $0.0 \%$ ) and PPV (Optec 6500, $30.0 \%$ vs. Visiotest, $0.0 \%$ ); and for participants $>50$ in near LP for sensitivity (Optec 6500, 53.9\% vs. Visiotest, $23.1 \%)$. The clearest differences between screeners with regard to computer use at work were in near LP for sensitivity (Optec $6500,42.9 \%$ vs. Visiotest, $0.0 \%$ ) and PPV (Optec 6500, 30.0\% vs. Visiotest, $0.0 \%$ ) in the group with $\leq 4 \mathrm{~h}$ of computer use.

\section{Concordance between the two visual screeners (Table 4)}

All results in the concordance study were classified as poor $(\kappa<0.40)$, except for concordance between the Optec 6500 and Visiotest for monocular VA and SA, which was moderate ( $\mathrm{\kappa}=0.42$ and $\mathrm{\kappa}=0.46$, respectively).

\section{Discussion}

The two vision screeners evaluated in this study both had low sensitivity, low PPV, high specificity, and high NPV, except in the case of monocular VA, which had high sensitivity. The tests with the lowest sensitivity were distance and near LP. False positive and false negative rates were considered to be acceptable for the majority of the tests and both screeners. Moreover, concordance between the two screeners and the visual examination conducted by the optometrist was classified as poor.

These results are similar to previous studies, which have shown high specificity and low sensitivity values ${ }^{14,15,17)}$. Nevertheless, only the study by Horberry et al. ${ }^{14)}$ included computer users in the evaluation (although the number of hours per day spent on computers was not mentioned). In our study, the stratified analysis according to the number of daily hours spent using a computer at work showed that the largest difference between screeners was the near LP measured in users spending $\leq 4 \mathrm{~h}$ /day using a computer.

Our findings show that the Visiotest obtained a lower number of false positives than the Optec 6500 in all tests, except for binocular VA and distance LP, which were similar. Our results showed fewer false positives than those obtained by Horberry et al. ${ }^{14)}$ and by Hansmaennel et al. ${ }^{15)}$, who found more than $50 \%$ false positives when measuring phorias and SA with a Visiotest model in studies conducted over 20 years ago. This improvement could be due to the evolution of the screener design. Our study shows false negative values below $50 \%$ in all tests and for both screeners, except for distance and near LP; these results are within ranges that are considered to be acceptable ${ }^{26)}$. It should be considered that we are referencing 
Table 3. Sensitivity (S), Specificity (SP), positive predictive value (PPV) and negative predictive value (NPV) when comparing Optec 6500 and Visiotest vision screeners with the visual examination conducted by an optometrist, stratified by sex, age and use of computer at work

\begin{tabular}{|c|c|c|c|c|c|c|c|c|c|c|c|c|c|}
\hline \multirow{3}{*}{ Test } & & \multicolumn{4}{|c|}{ Sex } & \multicolumn{4}{|c|}{ Age (years) } & \multicolumn{4}{|c|}{ Computer use at work (h/day) } \\
\hline & & \multicolumn{2}{|c|}{ Men } & \multicolumn{2}{|c|}{ Female } & \multicolumn{2}{|c|}{$\leq 50$} & \multicolumn{2}{|c|}{$>50$} & \multicolumn{2}{|r|}{$\leq 4$} & \multicolumn{2}{|r|}{$>4$} \\
\hline & & Optec & Visiotest & Optec & Visiotest & Optec & Visiotest & Optec & Visiotest & Optec & Visiotest & Optec & Visiotest \\
\hline \multirow{4}{*}{$\begin{array}{l}\text { Monocular } \mathrm{VA}^{\dagger} \\
(\log M A R)\end{array}$} & $S$ & 50.0 & 100.0 & 100.0 & 100.0 & - & - & 83.3 & 100.0 & 100.0 & 100.0 & 80.0 & 100.0 \\
\hline & $\mathrm{Sp}$ & 92.6 & 98.1 & 78.7 & 83.6 & 82.9 & 90.2 & 83.0 & 86.2 & 74.5 & 81.8 & 86.6 & 90.8 \\
\hline & PPV & 20.0 & 66.7 & 13.3 & 16.7 & 0.0 & 0.0 & 23.8 & 31.6 & 6.7 & 9.1 & 20.0 & 31.3 \\
\hline & NPV & 98.0 & 100.0 & 100.0 & 100.0 & 100.0 & 100.0 & 98.7 & 100.0 & 100.0 & 100.0 & 99.0 & 100.0 \\
\hline \multirow{4}{*}{$\begin{array}{l}\text { Binocular VA } \neq \\
(\log M A R)\end{array}$} & $\mathrm{S}$ & - & - & - & - & - & - & - & - & - & - & - & - \\
\hline & $\mathrm{Sp}$ & 100.0 & 96.4 & 98.4 & 96.8 & 100.0 & 95.1 & 98.0 & 98.0 & 100.0 & 92.9 & 98.4 & 98.4 \\
\hline & PPV & - & 0.0 & 0.0 & 0.0 & - & 0.0 & 0.0 & 0.0 & - & 0.0 & 0.0 & 0.0 \\
\hline & NPV & 100.0 & 100.0 & 100.0 & 100.0 & 100.0 & 100.0 & 100.0 & 100.0 & 100.0 & 100.0 & 100.0 & 100.0 \\
\hline \multirow[t]{4}{*}{$\mathrm{SA}(\operatorname{arcsec})$} & $\mathrm{S}$ & 44.4 & 66.7 & 63.6 & 63.6 & 62.5 & 50.0 & 56.5 & 69.6 & 60.0 & 70.0 & 55.0 & 65.0 \\
\hline & $\mathrm{Sp}$ & 73.7 & 68.4 & 61.0 & 68.3 & 57.6 & 75.8 & 74.1 & 59.3 & 50.0 & 72.2 & 71.4 & 66.7 \\
\hline & PPV & 44.4 & 50.0 & 46.7 & 51.9 & 26.3 & 33.3 & 65.0 & 59.3 & 40.0 & 58.3 & 47.8 & 48.1 \\
\hline & NPV & 73.7 & 81.3 & 75.8 & 77.8 & 86.4 & 86.2 & 66.7 & 69.6 & 69.2 & 81.3 & 76.9 & 80.0 \\
\hline \multirow[t]{4}{*}{ Distance LP $(\Delta)$} & $\mathrm{S}$ & 0.0 & 0.0 & 10.0 & 10.0 & 0.0 & 0.0 & 16.7 & 16.7 & 0.0 & 0.0 & 20.0 & 20.0 \\
\hline & $\mathrm{Sp}$ & 70.4 & 70.4 & 75.5 & 73.6 & 69.4 & 72.2 & 77.3 & 72.7 & 72.7 & 72.7 & 75.4 & 71.9 \\
\hline & PPV & 0.0 & 0.0 & 7.1 & 6.7 & 0.0 & 0.0 & 9.1 & 7.7 & 0.0 & 0.0 & 6.7 & 5.9 \\
\hline & NPV & 95.0 & 95.0 & 81.6 & 81.3 & 83.3 & 83.9 & 87.2 & 86.5 & 72.7 & 72.7 & 91.5 & 91.1 \\
\hline \multirow[t]{4}{*}{ Near LP $(\Delta)$} & $\mathrm{S}$ & 25.0 & 25.0 & 47.4 & 10.5 & 30.0 & 0.0 & 53.9 & 23.1 & 42.9 & 0.0 & 40.0 & 20.0 \\
\hline & $\mathrm{Sp}$ & 62.5 & 83.3 & 81.8 & 84.1 & 77.4 & 87.1 & 73.0 & 81.1 & 66.7 & 90.5 & 78.7 & 80.9 \\
\hline & PPV & 10.0 & 20.0 & 52.9 & 22.2 & 30.0 & 0.0 & 41.2 & 30.0 & 30.0 & 0.0 & 37.5 & 25.0 \\
\hline & NPV & 83.3 & 87.0 & 78.3 & 68.5 & 77.4 & 73.0 & 81.8 & 75.0 & 77.8 & 73.1 & 80.4 & 76.0 \\
\hline \multirow[t]{4}{*}{ Color vision $^{\S}$} & $\mathrm{S}$ & & - & & 50.0 & & - & & 50.0 & & - & & 50.0 \\
\hline & $\mathrm{Sp}$ & & 96.4 & & 88.5 & & 92.7 & & 89.6 & & 85.7 & & 93.3 \\
\hline & PPV & & 0.0 & & 12.5 & & 0.0 & & 16.7 & & 0.0 & & 20.0 \\
\hline & NPV & & 100.0 & & 98.2 & & 100.0 & & 97.7 & & 100.0 & & 98.2 \\
\hline
\end{tabular}

Abbreviations: VA, visual acuity; SA, stereo acuity; LP, lateral phoria; $\Delta$, prism diopters.

${ }^{\dagger}$ Monocular VA has been calculated for both eyes $(\mathrm{n}=182)$.

${ }^{\ddagger} \mathrm{S}$ and PPV could not be calculated as no altered test results were obtained according to the gold standard.

${ }^{\S}$ Test was not conducted with the Optec 6500 .

Table 4. Concordance between results obtained in the different visual examinations: Kappa coefficient ( $\kappa)$ and confidence interval at $95 \%(95 \% \mathrm{CI})$

\begin{tabular}{|c|c|c|c|c|c|c|}
\hline \multirow{2}{*}{ Test } & \multicolumn{2}{|c|}{ Optec 6500/Optometrist } & \multicolumn{2}{|c|}{ Visiotest/Optometrist } & \multicolumn{2}{|c|}{ Optec 6500/Visiotest } \\
\hline & $\kappa$ & $(95 \% \mathrm{CI})$ & $\kappa$ & $(95 \% \mathrm{CI})$ & $\kappa$ & $(95 \% \mathrm{CI})$ \\
\hline Monocular VA $(\log M A R)$ & 0.20 & $(0.04-0.36)$ & 0.33 & $(0.13-0.53)$ & 0.42 & $(0.25-0.59)$ \\
\hline Binocular $\mathrm{VA}^{\dagger}(\log M A R)$ & - & - & - & - & -0.02 & $(-0.04-0.01)$ \\
\hline $\mathrm{SA}(\operatorname{arcsec})$ & 0.22 & $(0.02-0.42)$ & 0.31 & $(0.11-0.50)$ & 0.46 & $(0.28-0.65)$ \\
\hline Distance LP $(\Delta)$ & -0.12 & $(-0.26-0.02)$ & -0.13 & $(-0.26-0.01)$ & 0.32 & $(0.10-0.54)$ \\
\hline Near LP $(\Delta)$ & 0.18 & $(-0.04-0.39)$ & -0.04 & $(-0.22-0.15)$ & 0.30 & $(0.09-0.51)$ \\
\hline Colour vision & & & 0.14 & $(-0.14-0.41)$ & & \\
\hline
\end{tabular}

Abbreviations: VA, visual acuity; SA, stereo acuity; LP, lateral phoria; $\Delta$, prism diopters.

${ }^{\dagger} \kappa$ could not be calculated as no altered test results were obtained according to the gold standard.

Test was not conducted with the Optec 6500 . 
screening that requires high NPV levels such as those obtained in this study.

The PPV was not high enough in those groups with a high prevalence (for instance, workers older than 50 years old) because the study participants were healthy. However, the NPV was high, which is the most useful value to detect those subjects who truly do not have the disease in a screening program. If a worker is diagnosed with altered tests by these screeners, the result should be confirmed with a subsequent clinical visual examination conducted by a visual health specialist.

Our study shows low concordance between the Optec 6500 and the Visiotest (and between each screener and the gold standard), leading to serious doubts regarding their use in practice. The differences in the ergonomic design of each screener and the different charts that each uses (as can be seen in Fig. 1) are the most likely reasons for the different results obtained by participants in the visual tests. The examiner can also influence the application of these diagnostic tests ${ }^{27)}$. However, we do not believe that this is the cause of the low concordance that we observed, as both examiners (the optometrist and the occupational health nurse) were trained prior to conducting the tests. Additionally, the tests were performed double blinded: both the participant and the occupational health nurse were unaware of the results of the visual examination conducted by the optometrist.

Some limitations must be considered in the interpretation of our results. Our study comprised a small sample size, particularly when compared with previous studies that have investigated these vision screeners. However, those were descriptive studies of morbidity in the working population, not validation studies as in the present case $^{28,29}$. The sample selection used in our investigation meant that this was a healthy population, without major pathologies. Further research should be performed in different populations to evaluate the variation of the predictive values according to disease prevalence ${ }^{30)}$. In fact, our study showed that PPVs were higher in subjects 50 years of age or older (compared with those under 50 years) in whom the prevalence of disease was higher.

Although the NPV shown in this study is an acceptable value for screening in visual health surveillance for workers who use computers, the low concordance shown could limit the utility of these results. In groups with a low prevalence of altered tests as in our study, the screeners would provide a good approximation to rule out alterations and to refer only patients with positive test results to a specialist. Our study thus provides a first approximation of the validity of these screeners. Further validation studies of these screeners are needed to establish their reliability by repeated measurements of the same participant with different examiners. Future studies should also be conducted with larger numbers of participants and including participants with different visual conditions.
Acknowledgments: This study has been partially funded by the Generalitat Valenciana (Conselleria de Sanidad 003/2009). The authors would like to thank the members of the Valencian Institute of Occupational Safety and Health (INVASSAT) for their collaboration.

\section{References}

1) Eurofound. Fifth European Working Conditions Survey 2012. [Online]. 2012. [cited 2015 Sep. 2]; Available from: URL: htt p://www.eurofound.europa.eu/publications/htmlfiles/ef1182.ht $\mathrm{m}$

2) Chu C, Rosenfield M, Portello JK, Benzoni JA, Collier JD. A comparison of symptoms after viewing text on a computer screen and hardcopy. Ophthalmic Physiol Opt 2011; 31(1): 29-32.

3) Blehm C, Vishnu S, Khattak A, Mitra S, Yee RW. Computer vision syndrome: a review. Surv Ophthalmol 2005; 50(3): 253-262.

4) Hayes JR, Sheedy JE, Stelmack JA, Heaney CA. Computer use, symptoms, and quality of life. Optom Vis Sci 2007; 84 (8): 738-744.

5) Rosenfield M. Computer vision syndrome: a review of ocular causes and potential treatments. Ophthalmic Physiol Opt 2011; 31(5): 502-515.

6) Iribarren R, Iribarren G, Fornaciari A. Visual function study in work with computer. Medicina (B Aires) 2002; 62(2): 141144 (in Spanish).

7) Uchino M, Schaumberg DA, Dogru M, et al. Prevalence of Dry Eye Disease among Japanese Visual Display Terminal Users. Ophthalmology 2008; 115(11): 1982-1988.

8) Portello JK, Rosenfield M, Bababekova Y, Estrada JM, Leon A. Computer-related visual symptoms in office workers. Ophthalmic Physiol Opt 2012; 32(5): 375-382.

9) Uchino M, Yokoi N, Dogru M, et al. Prevalence of dry eye disease and its risk factors in visual display terminal users: the osaka study. Am J Ophthalmol 2013; 156(4): 759-766.

10) Council Directive 90/270/EEC of 29 May 1990 on the minimum safety and health requirements for work with display screen equipment (fifth individual Directive within the meaning of Article 16 (1) of Directive 89/391/EEC) Official Journal of the European Communities. [Online]. 1990. [cited 2015 Sep. 2]; Available from: URL: http://eurlex.europa.eu/LexUri Serv/LexUriServ.do?uri=CONSLEG:1990L0270:20070627:E S:PDF.

11) Public Health Commission. Interterritorial Council of the National Health System. Specific Health Surveillance Protocol for Video Display Terminals. Ministry of Health and Consumer Affairs. [Online]. 1999. [cited 2015 Sep. 2]; Available from: URL: http://www.msssi.gob.es/ciudadanos/saludAmbLa boral/docs/datos.pdf.

12) National Institute of Research and Safety (NIRS). Display screens. Health and ergonomics. [Online]. 2014. [cited 2015 Sep. 2]; Available from: URL: http://www.inrs.fr/accueil/dms/ inrs/CataloguePapier/ED/TI-ED-924/ed924.pdf.

13) Health and Safety Executive. Work with display screen equip- 
ment. London, HSE Books. [Online]. 2003. [cited 2015 Sep. 2]; Available from: URL: http://www.hse.gov.uk/pubns/price d/126.pdf.

14) Horberry TJ, Gale AG, Taylor SP. Vision screeners for display screen equipment users: an experimental. Displays 1997; 17(2): 111-117.

15) Hansmaennel G, Becker F, Speeg-Schatz C. Essilor's Visiotest Evaluation. Proposal behavior in occcupational medicine at the results obtained Visiotest. Arch Mal Prof 1998; 59(2): 7683 (in French).

16) Le Mercier $C$. The visiotest in occupational medicine. Revue Francophone d'Orthoptie 2009; 2(2): $84-87$ (in French).

17) Totaro B, Assini R, Consonni D, et al. Adequacy and reliability of orthoanalyzer Ergovision for job-fitness evaluation. G Ital Med Lav Ergon 2007; 29(3): 250-251 (in Italian).

18) Bailey IL, Lovie-Kitchin JE. Visual acuity testing. From the laboratory to the clinic. Vision Res 2013; 90: 2-9.

19) Spalton DJ, Hitchings RA, Hunter P. Atlas of clinical ophthalmology. 3rd ed. Madrid: Elsevier; 2006.

20) Benjamin WJ. Borish's Clinical Refraction. 1st ed. Philadelphia: WB Sunders; 1998.

21) Griffin JR, Grisham JD. Binocular Anomalies: Diagnosis and Vision Therapy. 4th ed. Amsterdam: Butterworth-Heinemann; 2002.

22) Iregren A, Andersson M, Nylén P. Color vision and occupational chemical exposures: II. Visual functions in non-exposed subjects. Neurotoxicology 2002; 23(6): 735-745.
23) Bossuyt PM, Reitsma JB, Bruns DE, et al, for the STARD Group. Towards complete and accurate reporting of studies of diagnostic accuracy: The STARD Initiative. Clin Chem 2003; 49(1): 1-6.

24) Wilson EB. Probable inference, the law of succession, and statistical inference. J Am Stat Assoc 1927; 22: 209-212.

25) MacDermid JC, Brooks D, Solway S, Switzer-McIntyre S, Brosseau L, Graham ID. Reliability and validity of the AGREE instrument used by physical therapists in assessment of clinical practice guidelines. BMC Health Serv Res 2005; 5 (1): 18 .

26) Doménech JM, Granero R. Diagnostic Testings. Measures of morbidity and mortality. Sampling techniques. 1st ed. Barcelona: Signo; 1996.

27) Lumbreras B, Pascual E, Frasquet J, González-Salinas J, Rodríguez E, Hernández-Aguado I. Analysis for crystals in sinovial fluid: training of the analysts results in high consistency. Ann Rheum Dis 2005; 64(4): 612-615.

28) Barbini N, Squadroni R. ESTEV study on relationship between health, work and aging in Italy. Med Lav 2000; 91(4): 366-378 (in Italian).

29) Boissin JP, Peyresblanques J, Rollin JP, Marini F, Beaufils D. The vision of welders in France. J Fr Ophtalmol 2002; 25(8): 807-812 (in French).

30) Brenner H, Gefeller O. Variation of sensitivity, specificity, likelihood ratios and predictive values with disease prevalence. Stat Med 1997; 16(9): 981-991. 